American Journal of Environmental Sciences 6 (3): 253-259, 2010

ISSN 1553-345X

(C) 2010 Science Publications

\title{
Advective Heat Transport in an Unconfined Aquifer Induced by the Field Injection of an Open-Loop Groundwater Heat Pump
}

\author{
Stefano Lo Russo and Glenda Taddia \\ Department of Environment and Geo-Engineering (DITAG), \\ Politecnico di Torino-Land, C.so Duca degli Abruzzi, 2410129 Torino, Italy
}

\begin{abstract}
Problem statement: The increasing diffusion of low-enthalpy geothermal open-loop Groundwater Heat Pumps (GWHP) providing buildings air conditioning requires a careful assessment of the overall effects on groundwater system, especially in the urban areas. The impact on the groundwater temperature in the surrounding area of the re-injection well is directly linked to the aquifer properties. Physical processes affecting heat transport within an aquifer include advection (or convection) and hydrodynamic thermodispersion (diffusion and mechanical dispersion). If the groundwater flows, the advective components tend to dominate the heat transfer process within the aquifer and the diffusion can be considered negligible. This study illustrates the experimental results derived from the groundwater monitoring in the surrounding area of an injection well connected to an open-loop GWHP plant which has been installed in the "Politecnico di Torino" (NW Italy) for cooling some of the university buildings. Groundwater pumping and injection interfere only with the upper unconfined aquifer. Approach: After the description of the hydrogeological setting the authors examined the data deriving from multiparameter probes installed inside the pumping well (P2), the injection well (P4) and a downgradient piezometer (S2). Data refers to the summer 2009. To control the aquifer thermal stratification some multi-temporal temperature logs have been performed in the S2. Results: After the injection of warm water in P4 the plume arrived after 30 days in the S2. That delay is compatible with the calculated plume migration velocity $\left(1.27 \mathrm{~m} \mathrm{~d}^{-1}\right)$ and their respective distance $(35 \mathrm{~m})$. The natural temperature in the aquifer due to the switching-off of the GWHP plant has been reached after two month. The Electrical Conductivity (EC) values tend to vary out of phase with the temperature. The temperature logs in the $\mathrm{S} 2$ highlighted a thermal stratification in the aquifer due to a low vertical dispersion of the injected warm water. Conclusion: Experimental evidences seem to confirm the prevalence of heat advective transport component respect the dispersive phenomena. This hypothesis appears validated by the following evidences: (i) the calculated advective migration velocities are compatible with the calculated retardation factor and the temperature revealed in the S2, (ii) both the groundwater and the heat tend to flow horizontally due to the different values of horizontal and vertical hydraulic conductivity in the Unit 1 (thermal stratification) and (iii) the flowing water highlighted different geochemical characteristics during the time.
\end{abstract}

Key words: Advective transport, heat flow, low-enthalpy GWHP, Turin, Italy

\section{INTRODUCTION}

The Groundwater Heat Pump (GWHP) system is an open-loop system that withdraws water from a well or surface water, passes it through a heat exchanger and discharges the water into an injection well or nearby river (Lund et al., 2005). As an efficient use of natural energy, this system utilizing the relatively stable temperature of groundwater can achieve a higher coefficient of performance and offers a more energysaving solution than the conventional Air-Source Heat
Pump (ASHP) system (Blum et al., 2010). However, the benefit of utilizing groundwater may not be fully achieved everywhere because system performance depends significantly on hydrologic and geological conditions (for example, aquifer depth, groundwater quality, the cooling and heating pattern, building load) (Abu-Nada et al., 2008).

Depending on the use mode (heating or cooling), energy can be extracted or injected. Thus, the ambient aquifer temperature is disturbed and cold or warm plumes develop. In order to optimize the design and

Corresponding Author: Stefano Lo Russo, Department of Environment and Geo-Engineering (DITAG),

Politecnico di Torino-Land, C.so Duca degli Abruzzi, 2410129 Torino, Italy 
operation of GWHP systems, it is usually necessary to predict groundwater and heat flow and evaluate system performance comprehensively. The temperature distribution in the aquifer will affect the heat pump efficiency if the perturbed area reaches the extraction well (or that of other heat pumps installed in the surrounding areas) (Hecht-Mendez et al., 2010; Lo Russo and Civita, 2009; 2010; Nam and Ooka, 2010). In these situations, it is important to understand the effect of the heat on the groundwater system and to be able to predict consequences such as the accelerated precipitation of dissolved substances, or changes in the biological regimes. To this aim several simulation models have been intensively developed with different reliability of results. Although in several studies models were successfully applied for simulating heat transport within the aquifers, experimental studies which provided field data concerning heat transfer phenomena are not so diffuse (Hecht-Mendez et al., 2010).

In a composite medium, such as an aquifer, the properties of both the fluid phase and the solid phase play important roles in heat transport (Bear, 1972). The temperature disturbances due to injection induced are compensated by lateral conductive heat transport and by convection due to moving water. In addition, heat transfer from the aquifer system to adjacent aquitards or through the unsaturated zone to the atmosphere can be significant process for removing heat from the aquifer.

Physical processes affecting heat transport within an aquifer include advection (or convection), mechanical dispersion and diffusion (usually grouped into hydrodynamic thermodispersion) (Diao et al., 2004). Convection is an energy transport mechanism due to fluid motion inside the medium. When the flow field is caused by external forces, the transport is said to occur by forced convection (Carslaw and Jager, 1959). Free or natural convection, instead, occurs when the movement of water is due to density variations caused by temperature gradients (Sethi and Di Molfetta, 2007). The diffusion of heat depends on the thermal conductivity and heat capacity of the aquifer. Diffusion occurs by conductive transport in a solid or a liquid by a linear expression relating the heat flux to the temperature gradient. If there is a lack of groundwater flow the heat transport in the porous medium occurs only due to the diffusion. However under most conditions of groundwater natural flow, diffusion is insignificant and is neglected. At higher velocities and/or longer flow paths (higher Peclet number) mechanical dispersion is the predominant cause of mixing of the thermal plume and the effects of diffusion can be ignored.

In this study we discuss the first experimental results derived by the groundwater monitoring around an injection well of an open-loop GWHP which has been installed in the "Politecnico di Torino" for cooling some of the university buildings. The monitoring period covers the summer 2009. Two existing wells are present in the site, one useable for groundwater extraction (P2), the other for injection (P4). A piezometer (S2) in placed $35 \mathrm{~m}$ downgradient respect the P4.

Through multiparameter probes installed in the pumping and injection wells and inside the piezometer it is possible to control the movement of the warm plume over time during the operating period of the heat pump. The multi-temporal thermal $\operatorname{logs}$ in S2 highlighted the plume thermal stratification in the aquifer and tend to confirm the hypothesis about the prevailing advective transport component for heat flow.

\section{MATERIALS AND METHODS}

Site description: The site is located in the Turin urban district (NW Italy) at about $248 \mathrm{~m}$ asl. This flat area is mainly developed on the outwash plain constituted by several glaciofluvial coalescing fans connected to the Pleistocene-Holocene expansion phases of the Susa glacier. The plain extends between the external RivoliAvigliana Morainic Amphitheatre (RAMA-Susa Glacier) on the west side and the miocenic sequences of the Torino Hill on the east (Fig. 1).

Downhole log data in the study area indicate the presence of two lithologic zones with distinct hydraulic properties. Unit 1-(Middle Pleistocene-Holocene; from the surface to $48 \mathrm{~m}$ depth). Continental alluvial cover composed mainly of coarse gravel and sandy sediments (locally cemented) derived from alluvial fans aggraded by the Alpine rivers downstreaming towards the east. The base of Unit 1 (erosional surface) dips gently $(0.5 \%)$ towards the north-east, overlaying Unit 2.

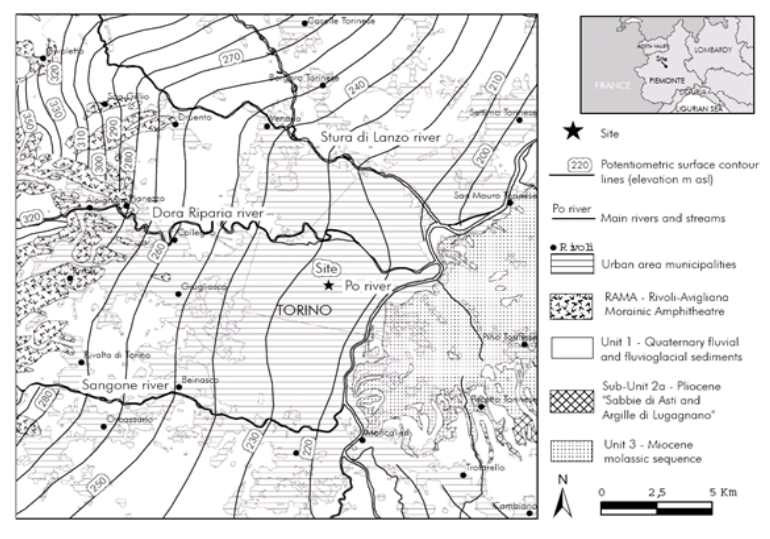

Fig. 1: Hydrogeological map of the Turin area and location of the site 
Am. J. Environ. Sci., 6 (3): 253-259, 2010

\begin{tabular}{lll}
\multicolumn{2}{l}{ Table 1: Nomenclature } \\
\hline Symbol & Variable & $\mathrm{Unit}$ \\
\hline $\mathrm{n}$ & Total porosity (void volume/total volume) & $(-)$ \\
$\mathrm{n}_{\mathrm{e}}$ & Effective porosity (always $<\mathrm{n})$ & $(-)$ \\
$\mathrm{Trans}$ & Aquifer transmissivity & $\left(\mathrm{m}^{2} \mathrm{sec}^{-1}\right)$ \\
$\mathrm{K}$ & Aquifer hydraulic conductivity & $\left(\mathrm{m} \mathrm{sec}^{-1}\right)$ \\
$\mathrm{dh} \mathrm{dL}^{-1}$ & Hydraulic gradient & $(-)$ \\
$\rho_{\mathrm{w}}$ & Density of the water & $\left(\mathrm{kg} \mathrm{m}^{-3}\right)$ \\
$\mathrm{C}_{\mathrm{w}}$ & Specific heat capacity of the water & $\left(\mathrm{J} \mathrm{kg}^{-1} \mathrm{~K}^{-1}\right)$ \\
$\rho_{\mathrm{w}} \mathrm{C}_{\mathrm{w}}$ & Volumetric heat capacity of the water & $\left(\mathrm{J} \mathrm{m}^{-3} \mathrm{~K}^{-1}\right)$ \\
$\mathrm{T}, \mathrm{T}_{\mathrm{s}}$ & Temperature, temperature of the solid & $(\mathrm{K})$ \\
$\mathrm{t}$ & time & $\left(\mathrm{sec}^{-}\right)$ \\
$\rho_{\mathrm{s}}$ & Density of the solid material (minerals) & $\left(\mathrm{kg} \mathrm{m}^{-3}\right)$ \\
$\mathrm{C}_{\mathrm{s}}$ & Specific heat capacity of the solid & $\left(\mathrm{J} \mathrm{kg}^{-1} \mathrm{~K}^{-1}\right)$ \\
$\rho_{\mathrm{s}} \mathrm{C}_{\mathrm{s}}$ & Volumetric heat capacity of the solid & $\left(\mathrm{J} \mathrm{m}^{-3} \mathrm{~K}^{-1}\right)$ \\
$\lambda_{\mathrm{m}}$ & Effective thermal conductivity of the & $\left(\mathrm{J} \mathrm{sec}^{-1} \mathrm{~m}^{-1} \mathrm{~K}^{-1}\right)$ \\
& porous media (water and solid) & \\
$\rho_{\mathrm{b}}$ & Dry bulk density $\rho_{\mathrm{b}}=(1-\mathrm{n}) \rho_{\mathrm{s}}$ & $\left(\mathrm{kg} \mathrm{m}^{-3}\right)$ \\
$\alpha, \alpha_{\mathrm{L}}$ & Dynamic dispersivity, Longitudinal & $(\mathrm{m})$ \\
& dispersivity & \\
$v_{\alpha}$ & Seepage average linear velocity & $\left(\mathrm{m} \mathrm{sec}^{-1}\right)$ \\
$\mathrm{q}_{\mathrm{h}}$ & Heat injection (source)/extraction (sink) & $\left(\mathrm{J} \mathrm{sec}^{-1} \mathrm{~m}^{-3}\right)$ \\
$\mathrm{q}_{\mathrm{ss}}$ & Volumetric flow rate per unit volume of & $\left(\mathrm{m} \mathrm{m} \mathrm{sec}^{3} \mathrm{~m}^{-3}\right)$ \\
& aquifer representing sources and sinks & \\
$\mathrm{C}_{\mathrm{ss}}$ & Concentration of the sources or sinks & $\left(\mathrm{kg} \mathrm{m}^{-3}\right)$ or $(\mathrm{K})$ \\
$\mathrm{R}$ & Retardation factor & $(-)$ \\
\hline
\end{tabular}

Unit 2-(Early Pliocene-Middle Pleistocene; from $48 \mathrm{~m}$ depth). Fossiliferous sandy-clayey layers with subordinate fine gravely and coarse sandy marine layers or by quartz-micaceous sands with no fossil evidences.

The unconfined aquifer that extends over the entire plain, including the location of the Politecnico site, is hydraulically connected to the main surface water drainage network in the area (i.e., the Dora Riparia and Po Rivers). This aquifer is hosted in Unit 1 and is quite vulnerable to pollution because of its shallow depth. The potentiometric surface, $21 \mathrm{~m}$ below ground level, shows a W-to-E undisturbed gradient of $\mathrm{dh} / \mathrm{dl} ; \mathrm{i}=$ $0.29 \%$ (Table 1 for nomenclature). The saturated thickness of the unconfined aquifer is about $27 \mathrm{~m}$.

The GWHP plant interferes only with the Unit 1 by means of a 40-m deep pumping well (P2) and one downgradient 47-m deep injection well (P4). A 35-m deep piezometer (S2) monitors the aquifer and is located downgradient respect $\mathrm{P} 4$. The respective distances are: $\mathrm{P} 2-\mathrm{P} 4=78 \mathrm{~m}, \mathrm{P} 4-\mathrm{S} 2=35 \mathrm{~m}, \mathrm{P} 2-\mathrm{S} 2=$ $109 \mathrm{~m}$.

First a step drawdown test was performed in $\mathrm{P} 4$ to evaluate the hydraulic properties of the Unit 1 . The test yielded a transmissivity (Trans 1 ) of $1.55 \times 10^{-2} \mathrm{~m}^{2} \mathrm{sec}^{-1}$. The hydraulic conductivity $\left(\mathrm{K}_{1}=5.74 \times 10^{-4} \mathrm{~m} \mathrm{sec}^{-1}\right)$ was calculated assuming and average saturated thickness of $27 \mathrm{~m}$. The effective porosity $n_{e}$ was assumed 0.12 . The undisturbed average linear velocity (Fetter, 1999) $v_{\alpha}\left(1.19 \mathrm{~m} \mathrm{~d}^{-1}\right)$ is thus calculated as follows:
$\mathrm{v}_{\mathrm{a}}=\frac{\mathrm{K}}{\mathrm{n}_{\mathrm{e}}} \cdot \frac{\mathrm{dh}}{\mathrm{dl}}$

During the injection of warm water in the P4 the hydraulic gradient increases up to $0.86 \%$ and thus the actual average velocity slightly grows up to $3.55 \mathrm{~m}$ day $^{-1}$ according with Eq. 1 .

The average P2 pumping (and P4 injection) rates during the GWHP functioning period were $8.5 \mathrm{~L} \mathrm{sec}^{-1}$.

Heat transport in the aquifer: For shallow unconfined aquifers five physical processes are relevant to the storage and movement of the thermal energy. These processes are (1) advection of the injected slug due to the natural gradient, (2) upward movement of the heated slug due to the buoyancy of the heated water heat (3) conduction within the aquifer, (4) heat transfer across the surface boundary and (5) seasonal variation in the background surface/aquifer temperatures (Palmer et al., 1992).

Owing to the analogies between solute and heat transport processes, the governing equations for transport in the subsurface can be represented by similar differential equations. The heat transport equation can be characterized by the principle of heat conservation, including conduction and convection (De Marsily, 1986):

$$
\begin{aligned}
& n \rho_{w} c_{w} \frac{\partial T}{\partial t}+(1-n) \rho_{s} c_{s} \frac{\partial T_{s}}{\partial t}= \\
& \operatorname{div}\left[\left(\lambda_{m}+n \rho_{w} c_{w} \alpha v_{a} \operatorname{gradT}\right)\right]-\operatorname{div}\left(n \rho_{w} c_{w} \alpha v_{a} T\right)+q_{h}
\end{aligned}
$$

Assuming that the temperature of water and soil are the same and that there is no net transfer from one phase to another, that is, thermal equilibrium (Nield and Bejan, 2006), the term on the left side of the heat transport equation can be expressed as follows:

$n \rho_{w} c_{w} \frac{\partial T}{\partial t}+(1-n) \rho_{s} c_{s} \frac{\partial T_{s}}{\partial t}=\rho_{m} c_{m} \frac{\partial T}{\partial t}$

The heat capacity of the porous medium $\rho_{\mathrm{m}} \mathrm{c}_{\mathrm{m}}$ can be computed as the weighted arithmetic mean of solid rock and pore fluid (Anderson, 2005; Hoeh and Cirpka, 2006):

$\rho_{\mathrm{m}} \mathrm{c}_{\mathrm{m}}=n \rho_{\mathrm{w}} \mathrm{c}_{\mathrm{w}}+(1-\mathrm{n}) \rho_{\mathrm{s}} \mathrm{c}_{\mathrm{s}}=n \rho_{\mathrm{w}} \mathrm{c}_{\mathrm{w}}+\rho_{\mathrm{b}} \mathrm{c}_{\mathrm{s}}$

Using Eq. 2 and 3 and rearranging them, Eq. 2 simplifies to: 


$$
\begin{aligned}
\left(\frac{\rho_{\mathrm{m}} \mathrm{c}_{\mathrm{m}}}{\mathrm{n} \rho_{\mathrm{w}} \mathrm{c}_{\mathrm{w}}}\right) \frac{\partial \mathrm{T}}{\partial \mathrm{t}} & =\operatorname{div}\left[\left(\frac{\lambda_{\mathrm{m}}}{\mathrm{n} \rho_{\mathrm{w}} \mathrm{c}_{\mathrm{w}}}+\alpha \mathrm{v}_{\mathrm{a}}\right) \operatorname{gradT}\right] \\
& -\operatorname{div}\left(\mathrm{v}_{\mathrm{a}} \mathrm{T}\right)+\frac{\mathrm{q}_{\mathrm{h}}}{\mathrm{n} \rho_{\mathrm{w}} \mathrm{c}_{\mathrm{w}}}
\end{aligned}
$$

One of the most significant effect is the advection of the thermal plume away form the injection well due to the natural hydraulic gradient. The advective velocity of the plume should be less than the natural groundwater velocity by a factor $R$, the thermal retardation factor, which can be derived by factoring out the appropriate terms from the heat transport equation. It is given as the ratio between volumetric heat capacity of the porous medium (total phase) and volumetric heat capacity of the water (mobile phase) (Shook, 2001):

$$
\mathrm{R}=\frac{\rho_{\mathrm{m}} \mathrm{c}_{\mathrm{m}}}{\mathrm{n} \rho_{\mathrm{w}} \mathrm{c}_{\mathrm{w}}}
$$

Assuming a total porosity of 0.25 and using the heat capacity of the aquifer $\rho_{\mathrm{m}} \mathrm{c}_{\mathrm{m}} 2.94 \times 10^{6} \mathrm{~J} \mathrm{~m}^{-3} \mathrm{~K}^{-1}$ computed by Eq. $4\left(\rho_{\mathrm{s}} \mathrm{C}_{\mathrm{s}}=2.52 \times 10^{6} \mathrm{~J} \mathrm{~m}^{-3} \mathrm{~K}^{-1}\right.$ and $\rho_{\mathrm{w}} \mathrm{C}_{\mathrm{w}}=4.2 \times 10^{6} \mathrm{~J} \mathrm{~m}^{-3} \mathrm{~K}^{-1}$ (Diersch, 2005)), $\mathrm{R}$ would equal approximately 2.8 in the saturated aquifer. The natural groundwater velocity would therefore almost three times the migration velocity of the thermal plume. This is approximately $1.27 \mathrm{~m} \mathrm{~d}^{-1}$ during the warm water injection and $0.43 \mathrm{~m} \mathrm{~d}^{-1}$ after the switching-off of the injection plant due to the variations in the hydraulic gradient.

Diffusion and dispersion coefficients: In the diffusion and dispersion term of the partial differential equation for heat transport (Eq. 2), we identify two parts. The first one is the pure thermal diffusivity driven only by the temperature gradient:

$$
\mathrm{D}_{\mathrm{h}}=\frac{\lambda_{\mathrm{m}}}{\mathrm{n} \rho_{\mathrm{w}} \mathrm{c}_{\mathrm{w}}}
$$

The second term of Eq. 2, the hydrodynamic dispersion $\alpha v_{\mathrm{a}}$, is a process driven by the differences in flow velocities at pore scale.

Sources and sinks: The source and sink term in the heat transport equation represent energy input or extraction:

$$
\mathrm{q}_{\mathrm{ss}} \mathrm{C}_{\mathrm{ss}}=\frac{\mathrm{q}_{\mathrm{h}}}{\rho_{\mathrm{w}} \mathrm{c}_{\mathrm{w}}}
$$

To be consistent with the dimensions relating the contaminant and heat transport, the unit Kelvin $(\mathrm{K})$ is equivalent to the concentration $\left(\mathrm{kg} \mathrm{m}^{-3}\right)$. Thus energy input/extraction is stated similar as a mass load per unit volume of aquifer.

Temperature dependency of the thermal parameters: Temperature has an influence on several physical parameters such as density and viscosity of water and thermal conductivity and heat capacity of the porous medium. Density and viscosity would directly affect the heat transport through the hydraulic conductivity and, consequently, the groundwater flow calculation. This influence is essentially independent of the hydrogeological system being simulated. However if the GWHPs groundwater temperature changes are restricted to some degrees the variation of fluid density and fluid viscosity with temperature is negligible. Moreover this inaccuracy seems acceptable in view of the general imprecision related to the determination of hydraulic conductivity, which is already reported as $27 \%$ for laboratory conditions (Butters and Duchateau, 2002).

Temperature variations can also promote free convection, which is a process driven by density differences as well as salinity concentration (Nield and Bejan, 2006). Free convection creates a buoyancy effect, making a denser fluid flow below the lighter one. However, in the absence of brine currents in shallow aquifers, density changes are weak (Kolditz et al., 1998). Buoyancy effects begin to be important for density differences larger than $0.8 \mathrm{~kg} \mathrm{~m}^{-3}$ (Schincariol and Schwartz, 1990). Neglecting salinity effects, a density variation of $0.8 \mathrm{~kg} \mathrm{~m}^{-3}$ implies a temperature change from $0-15^{\circ} \mathrm{C}$.

Finally the temperature influences the heat capacity and thermal conductivity (Clauser, 2003; Holzbecher, 1998). However even for larger differences (up to $60^{\circ} \mathrm{C}$ ), the error in the heat transport simulation is less than 3\% (Hecht-Mendez et al., 2010).

Based on these observations, the temperature dependency of the thermal parameters is not a real limitation for heat transport simulation of shallow geothermal systems if the maximum differences between injected hot water and natural conditions are below $10-15^{\circ} \mathrm{K}$. Density and viscosity variations with temperature can be considered negligible and also the buoyancy term in the momentum equation. For systems in which higher temperature changes are expected $\left(>10^{\circ} \mathrm{K}\right)$, instead, heat transport simulation should take into account the physical temperature dependencies of the thermal parameters. 


\section{RESULTS}

Monitoring: The GWHP plant started its operation on May 14th, 2009 and switch off on September, 20th 2009. Monitoring of hydraulic levels, electrical conductivity EC and temperature $\mathrm{T}$ in $\mathrm{P} 2, \mathrm{P} 4$ and $\mathrm{S} 2$ started in February 2009 and ended in November 2009. The data collected in P2 did not show significant changes during the monitoring period demonstrating no interference between pumping well (P2) and injection well (P4). Not being significant to evaluate the propagation of the thermal plume these data were not reported. On the contrary the data collected in P4 and S2 are important to understand the subsurface heat transport phenomena.

Analysis of those data clearly highlights three phases (Fig. 2). The phase 1 (February-May) corresponds to the period when the plant had not yet started. The $\mathrm{T}$ in the $\mathrm{P} 4$ and $\mathrm{S} 2$ is constant around $15^{\circ} \mathrm{C}$. The relative increase in the T P4 (end of March) is connected to a plant functioning test and is not revealed in the S2. The values of EC are almost stationary. The phase 2 (May-September) corresponds to the functioning period. The $\mathrm{T}$ and $\mathrm{EC}$ values recorded in the P4 and S2 vary considerably. The oscillations in the T P4 depends on the daily and weekly cycles of the heat pump. The maximum recorded value reaches $28.7^{\circ} \mathrm{C}$. The $\mathrm{T}$ recorded in the S2 clearly identify the aquifer response to the passage of the thermal plume with a significant delay (25-30 days) respect the injection in the $\mathrm{P} 4$. The $\mathrm{T}$ increase rate in $\mathrm{S} 2$ is approximately $1{ }^{\circ} \mathrm{C}$ day $^{-1}$ for the first 15 days, then slows down and levels off to $0.5^{\circ} \mathrm{C}$ day $^{-1}$ during the last part of the increasing period. The highest T measured in S2 was $22^{\circ} \mathrm{C}$ (September, 17th). The oscillations in the injection temperature in the $\mathrm{P} 4$ are smoothed but clearly revealed also in the $\mathrm{S} 2$. The $\mathrm{EC}$ values tend to vary out of phase with the temperature: When the $\mathrm{T}$ increases there is a reduction of EC.

The third phase (September-November) corresponds to the period after the plant closure. The parameter values gradually tend to restore the baseline. The T P4 decreases sharply while the T S2 reduces progressively losing about $1^{\circ} \mathrm{C}$ week ${ }^{-1}$ and reaching the initial temperature (around $15^{\circ} \mathrm{C}$ ) after two months. After the injection of warm water in $\mathrm{P} 4$ the plume arrives in the $\mathrm{S} 2$ with a time delay (about 30 days) that is compatible with the calculated migration velocity and the respective distance. Moreover, the time lag observed in S2 which is necessary to restore the natural temperature in the aquifer is compatible with the lower migration velocity (due to lower hydraulic gradient) connected to the switching-off of the GWHP plant.

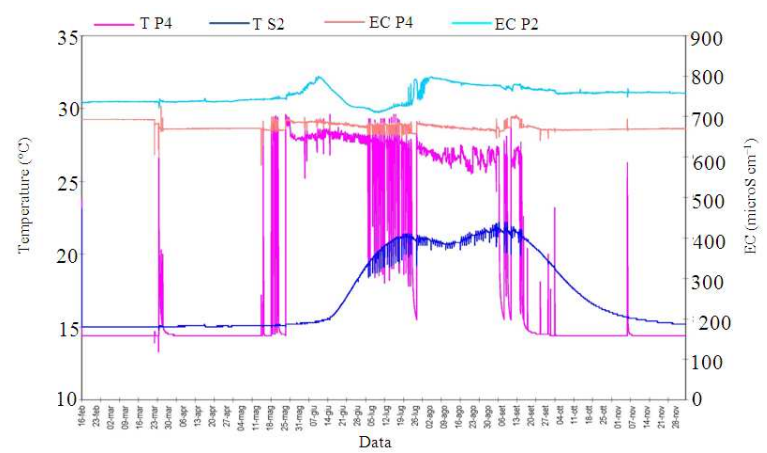

Fig. 2: Monitoring data

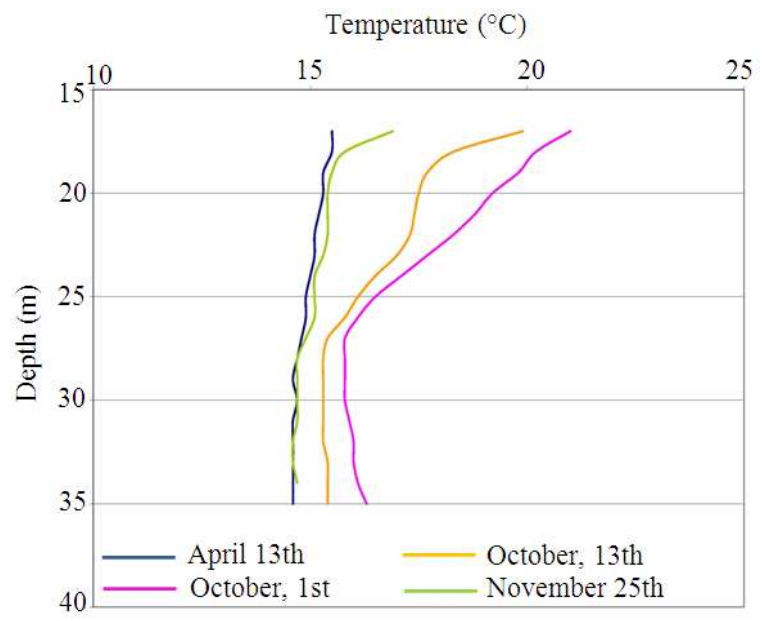

Fig. 3: Thermal logs

Multi-temporal thermal logs: The injection of the warm water in the P4 occurs by means of discharge in the upper part of the water column in the well. Therefore the thermal plume is originated by a point source located on the top of the water table. In order to verify the presence of a thermal stratification in the plume, one thermal $\log$ has been conducted in the S2 during the phase 1 (natural conditions). The result has been compared with those derived by 3 thermal logs conducted during the phase 3 (Fig. 3). Results highlighted a clear aquifer thermal stratification Temperature revealed in the S2 decrease with depth (Fig. 3). The progressive restoring of the initial temperature vertical homogeneity occurred only several weeks after the plant closure.

\section{DISCUSSION}

The experimental results demonstrated the propagation of the subsurface thermal plume during the injection of warm water and the progressive 
disappearance of the temperature anomaly with time. In particular, the simultaneous monitoring of groundwater temperatures in P4 and S2 held to assess both the overall width and the temporal evolution of the temperature variations in different control points.

These elements are very important to verify the initial assumptions on prevailing heat flow advective component within the investigated aquifer. If numerical modelling of the subsurface heat transport would be performed, the acquired field database can be used as control set for testing the reliability of the modelling results. In fact, the acquisition of field data permits to carry out accurate (and not theoretical) sensitivity analysis on the main parameters involved in the solution of the heat flow equations used by numerical simulations. Moreover comparison of field data and modelling assumptions can help individuating the actual role and the relative weight of each subsurface parameter.

In accordance with the available budget and the natural local conditions the efforts in the field investigation should therefore concentrate to assess with the greater accurateness the most significant parameters affecting the actual dynamics of heat transport.

\section{CONCLUSION}

Results seem to confirm the prevalence of heat advective transport component respect the dispersive phenomena. This hypothesis appears validated by the following evidences:

- The growing of S2 temperature as a marker of the warm plume transit highlighted a temporal delay (25-30 days) that is compatible with the P4-S2 distance $(35 \mathrm{~m})$ and the calculated migration velocities in the different hydrodynamic conditions $\left(1.27 \mathrm{~m} \mathrm{~d}^{-1}\right.$ during the warm water injection)

- Groundwater tend to flow horizontally due to the different values of horizontal and (lower) vertical hydraulic conductivity in the Unit 1 . The thermal stratification in the aquifer can be explained by the prevailing advection phenomena. Heat is transferred primarily by the flowing groundwater, horizontally

- The electrical conductivity appears to vary with an oscillatory behaviour, out of phase with respect to temperature. Uniquely difficult to explain, this phenomenon could be considered as a marker of different geochemical characteristics in the flowing water and thus a further confirmation of the prevailing heat advective phenomena in the flowing groundwater

\section{REFERENCES}

Abu-Nada, E., B. Akash I. Al-Hinti, A. Al-Sarkhi and S. Nijmeh et al., 2008. Modelling of a geothermal standing column well. Int. J. Energy Res. 32: 306-317. DOI: 10.1002/er.1355

Anderson, M.P., 2005. Heat as a ground water tracer. Ground Water, 43: 951-968. DOI: 10.1111/j.17456584.2005.00052.x

Bear, J. 1972. Dynamics of Fluids in Porous Media. 1st Edn., American Elsevier Publishing Company Inc, New York, ISBN: 10: 044400114X, pp: 764.

Blum, P., G. Campillo, W. Munch and T. Kolbel, 2010. $\mathrm{CO}_{2}$ savings of ground source heat pump systems-a regional analysis. Renew. Energy, 35: 122-127. DOI: 10.1016/j.renene.2009.03.034

Butters, G.L. and P. Duchateau, 2002. Continuous flow method for rapid measurement of soil hydraulic properties: I. Experimental considerations. Vadose Zone J., 1: 239-251.

Carslaw, H.S. and J.C. Jager, 1959. Conduction of Heat in Solids. 2nd Edn., Oxford University Press, New York, ISBN: 0198533683, pp: 510.

Clauser, C., 2003. Numerical Simulation of Reactive Flow in Hot Aquifers, SHEMAT and Processing SHEMAT. 1st Edn., Springer Verlag, Berlin, pp: 331.

De Marsily, G., 1986. Quantitative Hydrogeology: Groundwater hydrology for engineers. 1st Edn., Academic Press, Orlando, Florida, pp: 440.

Diao, N., Q. Li and Z. Fang, 2004. Heat transfer in ground heat exchangers with groundwater advection. Int. J. Thermal Sci., 43: 1203-1211. DOI: 10.1016/j.ijthermalsci.2004.04.009

Diersch, H.J.G., 2005. Reference Manual for FEFLOW®. WASY GmbH, Berlin, Germany, pp: 292.

Fetter, C.W., 1999. Contaminant Hydrogeology. 2nd Edn., Prentice-Hall, New-Jersey, USA., ISBN: 013-751215-5, pp: 500.

Hecht-Mendez, J., N. Molina-Giraldo, P. Blum and P. Bayer, 2010. Evaluating MT3DMS for heat transport simulation of closed geothermal systems. Ground Water. DOI: $10.1111 / \mathrm{j} .1745-$ 6584.2010.00678.x

Hoeh, E. and O.A. Cirpka, 2006. Assessing hyporheic zone dynamics in two alluvial flood plains of the Southern Alps using water temperature and tracers. Hydrology Earth Syst. Sci., 10: 553-563. DOI: 10.5194/hessd-3-335-2006

Holzbecher, E., 1998. Modelling Density-Driven Flow in Porous Media. 1st Edn., Springer Verlag, New York, ISBN: 3-540-63677-3, pp: 286. 
Kolditz, O., R. Ratke, H.J.G. Diersch and W. Zielke, 1998. Coupled groundwater flow and transport: 1. Verification of variable density flow and transport models. Adv. Water Resour., 21: 27-46. DOI: 10.1016/S0309-1708(96)00034-6

Lo Russo, S. and M.V. Civita, 2009. Open-loop groundwater heat pumps development for large buildings: A case study. Geothermics, 38: 335-345. DOI:10.1016/j.geothermics.2008.12.009

Lo Russo, S. and M.V. Civita, 2010. Hydrogeological and thermal characterization of shallow aquifers in the plain sector of Piemonte region (NW Italy): Implications for groundwater heat pumps diffusion. Environ. Earth Sci., 60: 703-713. DOI: 10.1007/s12665-009-0208-0

Lund, J.W., D.H. Freeston and T.L. Boyd, 2005. Direct application of geothermal energy: 2005 worldwide review. Geothermics, 34: 691-727. DOI: 10.1016/j.geothermics.2005.09.003

Nam, Y. and R. Ooka, 2010. Numerical simulation of ground heat and water transfer for groundwater heat pump system based on real-scale experiment. Energy Build. 42: 69-75. DOI: 10.1016/j.enbuild.2009.07.012
Nield, D.A. and A. Bejan, 2006. Convection in Porous Media. 3rd Edn., Springer, New York, ISBN: 0387290966, pp640.

Palmer, C.D., D.W. Blowes, E.O. Frind and J.W. Molson, 1992. Thermal energy storage in an unconfined aquifer 1. field injection experiment. Water Resour. Res., 28: 2845-2856. DOI: 10.1029/92WR01471

Schincariol, R.A. and F.W. Schwartz, 1990. An experimental investigation of variable-density flow and mixing in homogeneous and heterogeneous media. Water Resour. Res., 26: 2317-2329. DOI: 10.1029/WR026i010p02317

Sethi, R. and A. Di Molfetta, 2007. Heat transport modelling in an aquifer downgradient a municipal solid waste landfill in Italy. Am. J. Environ. Sci., 3: 106-110.

Shook, M.G., 2001. Predicting thermal breakthrough in heterogeneous media from tracer tests. Geothermics, 30: 573-589. DOI: 10.1016/S03756505(01)00015-3 